\title{
Transrektal ultrasonografi eșliğinde alınan prostat iğne biyopsisinin erektil fonksiyon üzerine etkisi
}

\author{
The effect of ultrasound guided prostate needle biopsy on the \\ erectile function

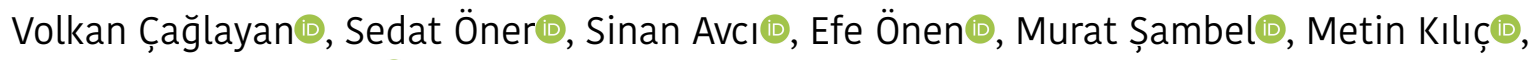 \\ Mustafa Murat Aydos(i)
}

\section{öz}

AMAÇ: Transrektal ultrasonografi eşliğinde prostat biyopsisinin (TRUS$\mathrm{Bx})$ erektil fonksiyon üzerine etkisini incelemektir.

GEREÇ ve YÖNTEM: Çalışmaya Mart 2013 - Aralık 2013 tarihleri arasında transrektal ultrasonografi eşliğinde prostat biyopsisi uygulanan 81 hasta dahil edildi. Hastalara işlemden önce ve 2., 4., 8. haftalarda Uluslar Arası Erektil İşlev - Erektil Fonksiyon (IIEF-EF) anket formu uygulandı. Kanser tanılı hastalar 4. hafta sonrasında çalışmadan çıkarıldı. Benign patolojili hastalar komplikasyon durumları bakımından alt gruplara ayrildı.

BULGULAR: Hastaların ortalama yaşı 62,9 (38-75) yıldı. IIEF-EF skoru 2. hafta kontrollerinde istatistiksel anlamlı olarak azaldı $(\mathrm{p}=0,004)$. Dördüncü hafta kontrollerinde benign patolojili hasta grubunda IIEFEF skoru başlangıç skoruyla karşılaştırıldığında istatistiksel anlamlı fark göstermezken $(\mathrm{p}=0,226)$, kanser tanılı hasta grubunda istatistiksel anlamlı olarak azaldı $(\mathrm{p}<0,001)$. Sekiz hafta sonunda benign patolojili hastaların IIEF-EF skorları, işlem öncesi skorlarla istatistiksel anlamlı fark göstermedi. İkinci hafta kontrollerinde, komplikasyon oluşmayan grupta istatistiksel anlamlı $(\mathrm{p}=0,029)$, komplikasyon oluşan grupta ise istatistiksel anlamlı olmayacak şekilde $(\mathrm{p}=0,051)$ IIEF-EF skorlarında düşme saptandı. Yaş, PSA değeri veya prostat volümü ile kontroller arasındaki skor farkları arasında korelasyon saptanmadı.

SONUÇ: Erektil fonksiyonlar, biyopsi sonrası erken dönemde olumsuz etkilenmektedir. Kanser tanilı hasta grubunda psikolojik faktörlerin erektil disfonksiyona neden olduğu düşünülmüştür. İşlem sonrası ortaya çıkan minör komplikasyonlar, gelişen geçici erektil disfonksiyon ile ilişkilendirilmemiştir.

Anahtar Kelimeler: Prostat biyopsisi, erektil disfonksiyon, transrektal ultrasonografi

Sağlık Bilimleri Üniversitesi, Bursa Yüksek Ihtisas Eğitim ve Araştırma Hastanesi, Üroloji Kliniği, Bursa, Türkiye

Yazışma Adresi/ Correspondence:

Dr. Efe Önen

SBÜ Bursa Yüksek Ihtisas Eğitim ve Araştırma Hastanesi, 16310 Bursa, Türkiye

Tel. $\quad$ +905052122383

E-mail: efe17@yahoo.com

Geliş/ Received: $\quad 09.05 .2018$

Kabul/ Accepted: 28.05 .2018

\section{ABSTRACT}

OBJECTIVE: To search the effect of transrectal ultrasonography-guided prostate biopsy (TRUS-Bx) on the erectile function.

MATERIAL and METHODS: The study included 81 patients who underwent TRUS-Bx between March 2013 and December 2013. International Index of Erectile Function - Erectile Function Domain (IIEF-EF) questionnaire was completed before, and 2nd, 4th, 8th week after the intervention. The patients with cancer diagnosis were excluded after the fourth week. The cancer-free patients were divided into subgroups in terms of complication status.

RESULTS: The mean age of the patients was 62.9 (38-75) years. IIEF-EF score decreased statistically significant in the 2nd week controls ( $\mathrm{p}=0.004)$. In the 4 th week control, there was no significant difference of the IIEF-EF score in the group of the cancer-free patients when compared with baseline score $(p=0.226)$; however, it decreased statistically significant in the group of patients with cancer diagnosis $(\mathrm{p}<0.001)$. In the 8 th week control, IIEF-EF score was not statistically significant in the group of cancer-free patients when compared with baseline score. In the 2nd week control, IIEF-EF score decreased statistically significant in the group of patients with no complications, decreased statistically not significant in the group of patients with complications. No correlation was detected between IIEF-EF score changes and prostate volume, PSA value, or age.

CONCLUSION: Erectile function is affected negatively in the postbiopsy early period. Psychological factors were thought to cause erectile dysfunction in the group of the patients with cancer diagnosis. The minor complications that occurred after the biopsy are not associated with the transient erectile dysfunction.

Keywords: Prostate biopsy, erectile dysfunction, transrectal ultrasonography

\section{Gíriș}

Transrektal ultrasonografi eşliğinde prostat biyopsisi (TRUS-Bx) 1989 yılında Hodge ve ark. tarafından ilk kez uygulandığından beri prostat kanseri tanısında standart yöntem olarak kabul edilmektedir. ${ }^{[1]}$ Her yıl dünyada 900.000'nin üstünde erkek prostat kanseri tanısı almaktadır. Tanı koyulan vakaların yaklaşık \%75'i prostat spesifik antijenin (PSA) yaygın olarak kullanıldığı ve sonrasında 
prostat biyopsisinin uygulandığı gelişmiş ülkelerden bildirilmektedir. ${ }^{[2]}$ Günümüzde, bu yöntem Amerika Birleşik Devletleri ve Avrupa'da yılda 1 milyondan fazla hastaya uygulanarak üroloji pratiğindeki en yaygın prosedürlerden biri haline gelmiştir. ${ }^{[3]}$

Her ne kadar TRUS-Bx hastalığın tanısında standart yöntem olsa da, işlem sonrası dönemde hematospermi, hematüri, rektal kanama, üriner retansiyon, üriner trakt enfeksiyonları ve ürosepsis gibi çeşitli komplikasyonlara sebep olabilmektedir. ${ }^{[4-7]}$ Literatürde, işlemin cinsel fonksiyonlar üzerine etkilerini inceleyen çalışmalarda, farklı sonuçlara rastlanılmaktadır. ${ }^{[8-14]}$

$\mathrm{Bu}$ çalışmada amacımız, kliniğimizde TRUS eşliğinde prostat biyopsisi yapılan hastaları işlem öncesi ve işlem sonrası belirli periyodlarda değerlendirmek ve prosedürün erektil fonksiyonlara etkilerini tespit etmektir.

\section{GEREÇ VE YÖNTEM}

Çalışmaya Mart 2013-Aralık 2013 tarihleri arasında prostat kanseri şüphesiyle TRUS eşliğinde ilk kez biyopsi uygulanan 81 hasta dahil edildi. Hastalar işlemden önce ve işlemden sonra 2., 4., 8. haftalarda, Ereksiyon İşlevi Uluslararası Değerlendirme (International Index of Erectile Function IIEF) formunun valide edilmiş Türkçe tercümesi ile değerlendirildi. ${ }^{[15]}$ Erektil disfonksiyon (ED) şiddeti IIEF erektil fonksiyon (EF) alt grup skorlarına göre; 1-10 puan şiddetli, 11-16 puan orta ve 17-25 puan hafif ED olarak sınıfland1rıldı. ${ }^{[16]}$ Çalışmamız için hastanemiz etik kurulundan onay alındı (2013/9/25 sayılı etik kurul onayı).

Çalışmamızda hastaların anormal rektal muayenesi ve/veya serum PSA seviyeleri 2,5 ng/mL'nin üzerinde olması prostat biyopsi endikasyonumuzu oluşturdu.

İşlem öncesinde sondalı olan ve işlem öncesi yeterli EF'nin

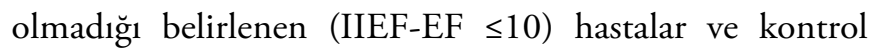
periyodlarında cinsel ilişkide bulunmayan hastalar çalışma dışı bırakıldı. İşlemden sonra gelişen komplikasyonlar Clavien derecelendirilmesine göre sınıflandırıldı. Clavien derece 2 ve daha ileri derecede komplikasyonlar gelişen hastalar (üriner retansiyon, enfektif tablo, makroskopik pıhtılı hematüri) çalışma dışı bırakıldı. Patoloji sonuçları kaydedildi. Patoloji sonucu malign olan hastalar sekizinci haftada çalışma dışı bırakıldı. Hastalar komplikasyon olup olmamasına göre iki gruba ayrıldı.

İşlem öncesinde tüm hastalardan idrar kültürü çalışıldı. İdrar kültüründe üreme olan hastaların uygun antibiyoterapi sonrası steril idrarı görüldükten sonra, tekrar PSA ölçümü yapıldı ve biyopsi ihtiyacı gözden geçirildi.
Hastaların yaşı, PSA düzeyleri, prostat hacimleri kaydedilerek, işlem sonrasında EF'ye etkileri değerlendirildi.

Tüm hastalara biyopsi işleminden bir gün önce başlanan ve sonrasında üç gün devam eden siprofloksasin $500 \mathrm{mg}$ oral yolla günde iki doz olacak şekilde reçete edildi. Barsak temizliği için, biyopsi sabahı lavman intrarektal olarak tüm hastalara uygulandı. İşlem sonrasında erken dönemde (üç gün) kullanılması önerisiyle, oral analjezikler de reçeteye eklendi.

Hastalar sol lateral dekübit pozisyonda, kalçalar ve dizler fleksiyonda olacak şekilde yatırıldı. Tüm hastalara intrarektal \%2'lik lidokainli jel uygulanarak lokal anestezi sağlandı. TRUS görüntüleme için General Electric LOGIQ 100 $\mathrm{PRO}^{\circ}$ serisi ultrasonografi cihazı ile en geniş çapı $23 \mathrm{~mm}$ olan 6,5 MHz rektal prob kullanıldı. Her hastadan biyopsi örnekleri $30 \mathrm{~cm} 18$ Gauge tam otomatik biyopsi iğnesi kullanılarak 12 kor şeklinde alındı.

\section{İstatistiksel analiz}

Değişkenlerin normal dağılıma uygun olmamalarından dolayı, non-parametrik istatistiksel testlerle karşılaştırma yapılmıştır. Gruplar arası karşılaştırmalarda Mann-Whitney U ve Kruskal-Wallis testleri, bağımlı gruplar için Wilcoxon testi, kategorik veriler içinse Ki-kare ve Fisher testleri kullanılmıştır; p değerinin <0,05 olduğu durumlar istatistiksel olarak anlamlı kabul edilmiştir.

\section{BULGULAR}

Hastaların ortalama yaşı 62,9 (38-75), ortalama PSA değeri $11,93(2,1-75,3) \mathrm{ng} / \mathrm{dL}$, ortalama prostat hacmi ise 68,4 (20-310) cc, ortalama vücut-kitle indeksi 22,52 (1633) $\mathrm{kg} / \mathrm{m}^{2}$ idi (Tablo 1).

Tablo 1. Hastaların demografik özellikleri

\begin{tabular}{lc} 
Yaş (yıl) & $62,9(38-75)$ \\
Prostat volümü (cc) & $68,4(20-310)$ \\
PSA değeri ( $\mathrm{ng} / \mathrm{dL})$ & $11,93(2,1-75,3)$ \\
Ortalama BMI (kg/m2) & $22,52(16-33)$ \\
Diabet $(\mathrm{n})$ & 8 \\
Hipertansiyon (n) & 7 \\
Kronik Obstruktif Akciğer Hastalığı (n) & 3 \\
Koroner Arter Hastalığı (n) & 5 \\
\hline
\end{tabular}

Altmış bir hastada benign (\%75,3), 20 hastada malign $(\% 24,7)$ patolojik tanı konulmuştur. Kanser tanısı koyulan hastalar, 4. hafta kontrolünden sonra definitif tedaviye yönlendirilmeleri sebebiyle 8 . haftada değerlendirilememişlerdir. Tüm hastaların ve patolojik alt grupların ilk dört 
Tablo 2. Sekiz haftalık IIEF-EF değerlendirilmesi

\begin{tabular}{|c|c|c|c|c|c|c|c|}
\hline & Başlangıç & Hafta 2 & $p h 2-0$ & Hafta 4 & $p h 4-0$ & Hafta 8 & $p h 8-0$ \\
\hline \multicolumn{8}{|l|}{ IIEF-EF skorları } \\
\hline Tüm hastalar(n=81) & $24(11-30)$ & $24(8-30)$ & 0,004 & $22(6-30)$ & 0,002 & & \\
\hline Benign hastalar $(n=61)$ & $24(11-30)$ & $24(9-30)$ & 0,011 & $25(10-30)$ & 0,226 & $25(10-30)$ & 0,212 \\
\hline Kanserli hastalar $(n=20)$ & $25(10-30)$ & $24(8-30)$ & 0,141 & $17,5(6-30)$ & $<0,001$ & & \\
\hline
\end{tabular}

IIEF-EF: International Index of Erectyl Function-Erectyl Function Domain, p h2-0: 2. hafta ile başlangıç skorunun karşılaştırılmasının p değeri, p h4-0: 4. hafta ile başlangıç skorunun karşılaştırılmasının $p$ değeri, $p$ h8-0: 8. hafta ile başlangıç skorunun karşılaştırılmasının $p$ değeri

haftadaki ve sekiz hafta izlenen benign patolojili hastaların değerlendirilmeleri Tablo 2'de gösterilmiştir.

Tüm hastalar değerlendirildiğinde, ilk kontrollerde total skorlarda istatistiksel olarak anlamlı azalma saptanmıştır $(\mathrm{p}=0,004)$. İşlemden dört hafta sonra yapılan kontrollerde, sadece benign patolojili hastalar değerlendirildiğinde, total skorlar işlem öncesindeki değerlerle istatistiksel anlamlı farklılık göstermemektedir $(\mathrm{p}=0,226)$.

Hastalar komplikasyon olup olmamasına göre iki gruba ayrılmıştır. İşlem sonrasında gelişen komplikasyonlar Clavien sınıflamasına göre derecelendirilmiştir. Otuz iki hastada komplikasyon gelişmiştir. Çalışmamızda, 10 hastada hematospermi, dokuz hastada hematüri, 13 hastada iki veya daha fazla komplikasyona rastlanılmıştır (Tablo 3). Komplikasyon durumunun işlem sonrası gelişen geçici skor düşmesine etkisinin incelenmesi açısından, iki grubun işlem öncesi ve ilk kontrollerdeki skorları karşılaştırılmıştır (Tablo 4).

Tablo 3. Görülen komplikasyonlar ve oranları.

\begin{tabular}{lcc}
\hline Komplikasyonla & Sayı & $\%$ \\
\hline Hematospermi & 22 & 27,2 \\
Hematüri & 21 & 25,9 \\
Rektal kanama & 4 & 4,9 \\
\hline
\end{tabular}

Tablo 4. Komplikasyon durumunun erektil fonksiyonlara etkisi

\begin{tabular}{|c|c|c|c|}
\hline & Başlangıç & Hafta 2 & $p h 2-0$ \\
\hline \multicolumn{4}{|c|}{ Ortalama IIEF-EF skorları } \\
\hline $\begin{array}{l}\text { Komplikasyon (-) } \\
(n=32)\end{array}$ & $22,43(11-30)$ & $21,8(8-30)$ & 0,029 \\
\hline $\begin{array}{l}\text { Komplikasyon }(+) \\
(n=49)\end{array}$ & $24,03(11-30)$ & $23,63(11-30)$ & 0,051 \\
\hline
\end{tabular}

Hastaların yaşı, PSA değerleri ve prostat volümleri ile kontrol periyodları arasındaki skor farklılıkları arasında korelasyon tespit edilmemiştir.

\section{TARTIȘMA}

Hastaların parmakla rektal muayenesinde anormal bir bulgunun tespit edilmesi veya PSA değerlerinde yükseklik saptanması, prostat kanseri olasılığını akla getirmektedir. Bu hastaların kesin tanısı için prostat iğne biyopsisi en sık kullanılan tanısal yöntem olup, prostat kanserinin patolojik tanısı vakaların büyük bir kısmında TRUS-Bx ile konulmaktadır. ${ }^{[17]}$ Amerika Üroloji Derneği (AUA) güncel kılavuzunda, optimal ilk biyopsi şekli olarak TRUS eşliğinde uzak lateral bölgeleri ve apekside içine alacak şekilde 12 kor biyopsi önerilmektedir. ${ }^{[18]}$ Son zamanlarda yapılan bir meta-analizde, klinik olarak anlamlı prostat kanserine tanı koymakta multiparametrik manyetik rezonans görüntüleme kılavuzluğunda biyopsinin daha başarılı olduğu gösterilmiştir. ${ }^{[19]} \mathrm{Bu}$ işlemin henüz fazla yaygın olmaması, uzun sürmesi ve ekonomik etmenler sebebiyle, TRUS eşliğinde sistematik biyopsi hala prostat kanseri tanısında standart yöntem olarak kabul edilmektedir.

İşlemin invaziv özellik taşıması ve özellikle de transrektal yolla yapılması, bir takım komplikasyonları olası hale getirmektedir. Bireyin günlük yaşam aktivitelerini etkileyecek bir yöntem olduğundan, işlem sonrası dönemde hastanın ve hekimin hazırlıklı olması gerekmektedir.

Christofos ve ark., TRUS-Bx uyguladıkları, medyan yaşı 61,51 yll, medyan PSA değeri 7,9 ng/dl ve medyan prostat hacmi 58,37 cc olan 46 hastayı, işlem günü, işlem sonrası birinci ve üçüncü aylarda IIEF-5 ile değerlendirmişlerdir. Kontroller sırasında istatistiksel anlamlı olarak skorlarda azalma saptanmamıştır. ${ }^{[8]}$

Klein ve ark., prostat kanseri şüphesiyle TRUS-Bx uyguladıkları 198 hastayı işlem sonrası EF açısından değerlendirmiştir. Hastaları üç gruba ayırmış olup, ilk gruba sadece intrarektal lidokain jel (71 hasta), ikinci gruba intrarektal lidokain jele ek olarak periprostatik sinir blokajı (74 hasta), daha öncesinde negatif biyopsisi olan ve PSA yüksekliği devam eden üçüncü gruba ise (53 hasta) satürasyon biyopsisi öncesi sadece periprostatik sinir blokajı uygulamışlardır. 
Hastaların ortalama yaşı 66,1 yıl, ortalama PSA değeri 9,1 $\mathrm{ng} / \mathrm{dL}$, ortalama prostat hacmi ise 44,94 cc idi. Hastalar, işlem öncesi, işlem sonrası birinci, dördüncü ve on ikinci haftalarda IIEF-5 ile değerlendirilmişlerdir. Çalışma sonucunda, periprostatik sinir blokajı ve alınan biyopsi sayısından bağımsız olarak EF’nin geçici olarak etkilendiği gösterilmiştir. IIEF-EF skorundaki azalmanın, standart biyopsi alınan ilk iki grupta 4 . haftada sebat ettiği görülmüştür. ${ }^{[9]}$

Akbal ve ark., PSA yüksekliği nedeniyle daha öncesinde TRUS-Bx uygulanan ve patolojisi benign olarak rapor edilen, ancak PSA yüksekliği devam eden 150 hastaya uyguladıkları ortalama 22 kor (en düşük: 20 kor, en yüksek: 30 kor) satürasyon biyopsisinin $\mathrm{EF}$ üzerine etkilerini incelemişlerdir. Hastaların medyan yaşı 62 (48-78), medyan PSA değeri $7,8 \mathrm{ng} / \mathrm{mL}(1,2-28,9)$ ve medyan prostat hacmi 45 cc (18-162) olarak saptanmıştır. Biyopsi işlemi öncesi hastalar beş maddelik uluslararası EF indeksi (IIEF5) ve altı maddelik IIEF-EF ile değerlendirilmiştir. Patoloji sonucu benign sonuçlanan 88 hasta, biyopsi sonrası birinci ve altıncı aylarda tekrar değerlendirilmişlerdir. İşlem öncesi potent olduğu bilinen bu hastaların \%11,6'sında işlem sonrası birinci ayda ED geliştiğini belirlemişlerdir. İşlem sonrası altıncı ay kontrollerinde ise EF'nin işlem öncesi değerlere döndüğü izlenmiştir. Akbal ve ark. bu çalışmada, satürasyon biyopsisinin hastalarda geçici ED'ye neden olduğu sonucuna varmışlardır. ${ }^{[10]}$

Aktoz ve ark., prostat biyopsisi uygulanan ve patoloji sonucu benign olan 62 hastayı EF açısından IIEF-5 ile işlem öncesi, işlem sonrası birinci ve üçüncü aylarda değerlendirmişlerdir. İlk kontroldeki ortalama skor işlem öncesi ortalama skora göre istatistiksel anlamlı düşüş gösterse de, üçüncü ay ortalama skoru ile başlangıç skoru arasında anlamlı fark saptanmamıştır. ${ }^{[11]}$

Tuncel ve ark.'nın yaptığı çalışmada, prostat biyopsisi uygulanan 97 hasta işlem öncesinde, işlem sonrası birinci ay ve altıncı ayda IIEF-5 ile değerlendirilmiştir. Bu çalışmanın sonucunda, birinci ve altıncı aylardaki skorların işlem öncesi skorlara göre istatistiksel anlamlı olarak azaldığı gösterilmiştir. ${ }^{[12]}$

Bizim çalışmamız işlemin geçici olarak ED'ye neden olması bakımından bahsedilen çalışmalarla benzerlik gösterse de, işlem öncesi skorlara dönmek için gerekli periyod açısından farklılık göstermektedir. Bulgularımıza göre, işlemden sonra iki hafta içinde oluşan cinsel fonksiyonlardaki gerileme, birinci ay kontrollerinde başlangıç seviyesine yükselmektedir.

Helfand ve ark.'nın prostat kanseri şüphesiyle 12 kor TRUS-Bx uyguladıkları 85 hasta üzerinde yaptıkları çalışmada, işlem öncesi IIEF skoru ile işlem sonrası IIEF skorları arasında istatistiksel olarak anlamlı fark bulunmamıştır. Fakat, patoloji sonucu adenokarsinom olan hasta grubu göz önüne alındığında, işlem öncesi ve sonrası IIEF skorları arasında büyük farklılıklar vardır. Bu çalışmada araştırmacılar, malign biyopsi sonucunun psikolojik ED’ye sebep olduğunu söylemişlerdir. ${ }^{[13]}$ Çalışmamızda, kanser tanısı alan hastaları ayrı bir grup olarak incelediğimizde, birinci ay kontrollerinde IIEF-EF skorlarında istatistiksel anlamlı düşüş $(\mathrm{p}<0,001)$ dikkat çekmektedir. Çalışmamızda anksiyete veya depresyon skorlarını ölçen anketler uygulanmasa da, kanser tanısı öğrenildikten sonra ortaya çıkan psikolojik stresin ED’ye neden olduğu açıkça görülmektedir.

Fujita ve ark.'nın 2009 yılında yayımlanan çalışmasında, prostat kanseri tanısı konulmuş ve aktif izlemdeki 231 hasta, seri biyopsilerin EF'ye etkileri bakımından takip edilmiştir. Çalışma sonucunda seri prostat biyopsilerinin ED gelişmesi açısından risk oluşturduğu ve oluşan bu riskin özellikle üç veya daha fazla biyopsi yapılan hastalarda daha anlamlı olduğu saptanmıştır. ${ }^{[14]}$

Çalışmamızda, işlem sonrasında gelişen komplikasyonlar Clavien sınıflamasına göre derecelendirilmiştir. Bazı çalışmalarda olduğu gibi üç günden fazla devam eden hematüri, üç günden fazla devam eden hematospermi ve 24 saatten uzun süren rektal kanama Clavien derece 1 komplikasyon olarak değerlendirilmiştir. ${ }^{[20]}$ Makroskopik pıhtılı hematüri ve enfektif durumlar gibi yüksek derece komplikasyonların skorları kesin olarak düşüreceği düşünüldüğü için, bu hastaların çalışma dışı bırakılması uygun görülmüştür. Bildiğimiz kadarıla, literatürde komplikasyon durumunun işlem sonrasında meydana gelebilecek EF'deki değişikliklerle ilişkisini gösteren bir çalışma bulunmamaktadır. Çalışmamızda, komplikasyon durumuna göre hastalar iki gruba ayrılıp incelendiğinde, komplikasyon olmayan grupta istatistiksel anlamlı $(\mathrm{p}=0,029)$, komplikasyon olan grupta ise sınırda istatistiksel anlamlı olmayan $(\mathrm{p}=0,051)$ skor düşüşleri saptanmıştır. Bu sonuçlara göre, işlemden sonra gelişen minör komplikasyonların sürecin doğal bir parçası olduğunu ve EF'de oluşan geçici gerilemeyle ilişkili olmadığını düşünmekteyiz.

\section{Çalıșmanın kısıtıııkları}

Anket çalışması olması, düşük hasta sayısı, biyopsi öncesinde detaylı hormon analizinin olmaması, IPSS ve idrar akım hızlarını, ayrıca anksiyeteyi ya da depresyon seviyelerini ölçen testlerin uygulanmaması, çalışmamızın önemli eksikleridir. 


\section{SONUÇ}

TRUS-Bx, işlem sonrası erken dönemde EF'yi olumsuz yönde etkileyen bir yöntemdir. IIEF-EF skorlarındaki düşüşler, hastanın yaşı, prostat volümü ve PSA değerinden bağımsızdır. Kanser tanısı alan hastalarda psikolojik ED gelişmesi beklenen bir durumdur. İşlem sonrasında gelişebilecek olan minör komplikasyonlar, hastalarda oluşan geçici ED'yi öngörmede etkili bulgular değildir.

\section{Hakem Değerlendirmesi}

Dış bağımsız

Çıkar Çatışması

Yazarlar çıkar ilişkisi olmadığını beyan etmişlerdir.

\section{Finansal Destek}

Herhangi bir mali destek alınmamıștır.

\section{Peer-review}

Externally peer-reviewed.

\section{Conflict of Interest}

No conflict of interest was declared by the authors.

Financial Disclosure

No financial disclosure was received.

\section{KAYNAKLAR}

1. Hodge KK, McNeal JE, Terris MK, Stamey TA. Random systematic versus ultrasound guided transrectal core biopsies of the prostate. J Urol 1989; 142:71-4.

2. Ferlay J, Shin HR, Bray F, Forman D, Mathers C, Parkin DM. Estimates of worldwide burden of cancer in 2008: GLOBOCAN 2008. Int J Cancer 2010;127:2893-917. [CrossRef]

3. Loeb S, Vellekoop A, Ahmed HU, Catto J, Emberton M, Nam R, et al. Systemic review of complications of prostate biopsy. Eur Urol 2013;64:876-92. [CrossRef]

4. Heidenreich A, Bastian PJ, Bellmunt J, Bolla M, Joniau S, van der Kwast T, et al. EAU guidelines on prostate cancer. part 1: screening, diagnosis, and local treatment with curative intent -update 2013. Eur Urol 2014;65:124-37. [CrossRef]

5. Ganeswaran D, Sweeney C, Yousif F, Lang S, Goodman C, Nabi G. Population-based linkage of health records to detect urological complications and hospitalisation following transrectal ultrasoundguided biopsies in men suspected of prostate cancer. World J Urol 2012;32:309-15. [CrossRef]

6. Li H, Yan W, Zhou Y, Ji Z, Chen J. Transperineal ultrasoundguided saturation biopsies using 11-region template of prostate: report of 303 cases. Urology 2007;70:1157-61. [CrossRef]

7. Chiang IN, Chang SJ, Pu YS, Huang KH, Yu HJ, Huang CY. Major complications and associated risk factors of transrectal ultrasound guided prostate needle biopsy: a retrospective study of 1875 cases in Taiwan. J Formos Med Assoc 2007;106:929-34. [CrossRef]
8. Chrisofos M, Papatsoris AG, Dellis A, Varkarakis IM, Skolarikos A, Deliveliotis C. Can prostate biopsies affect erectile function? Andrologia 2006;38:79-83. [CrossRef]

9. Klein T, Palisaar RJ, Holz A, Brock M, Noldus J, Hinkel A. The impact of prostate biopsy and periprostatic nerve block on erectile and voiding function: a prospective study. J Urol 2010;184:144752. [CrossRef]

10. Akbal C, Türker P, Tavukçu HH, Simşek F, Türkeri L. Erectile function in prostate cancer-free patients who underwent prostate saturation biopsy. Eur Urol 2008;53:540-5. [CrossRef]

11. Aktoz T, Kaplan M, Turan U, Memis D, Atakan IH, Inci O. 'Multimodal' approach to management of prostate biopsy pain and effects on sexual function: efficacy of levobupivacaine adjuvant to diclofenac sodium -a prospective randomized trial. Andrologia 2010;42:35-40. [CrossRef]

12. Tuncel A, Kirilmaz U, Nalcacioglu V, Aslan Y, Polat F, Atan A. The impact of transrectal prostate needle biopsy on sexuality in men and their female partners. Urology 2008;71:1128-31. [CrossRef]

13. Helfand BT, Glaser AP, Rimar K, Zargaroff S, Hedges J, McGuire $\mathrm{BB}$, et al. Prostate cancer diagnosis is associated with an increased risk of erectile dysfunction after prostate biopsy. BJU Int 2013;111:38-43. [CrossRef]

14. Fujita K, Landis P, McNeil BK, Pavlovich CP. Serial prostate biopsies are associated with an increased risk of erectile dysfunction in men with prostate cancer on active surveillance. J Urol 2009;182:26649. [CrossRef]

15. Rosen RC, Riley A, Wagner G, Osterloh IH, Kirkpatrick J, Mishra A. The international index of erectile function (IIEF): a multidimensional scale for assessment of erectile dysfunction. Urology 1997;49:822-30.

16. Cappelleri JC, Rosen RC, Smith MD, Mishra A, Osterloh IH. Diagnostic evaluation of the erectile function domain of the international Index of Erectile Function. Urology 1999;54:346-51.

17. Heidenreich A, Bellmunt J, Bolla M, Joniau S, Mason M, Matveev $\mathrm{V}$, et al. EAU guidelines on prostate cancer. Part 1: screening, diagnosis, and treatment of clinically localised disease. Eur Urol 2011;59:61-71. [CrossRef]

18. Bjurlin MA, Carter HB, Schellhammer P, Cookson MS, Gomella LG, Troyer D, et al. Optimization of initial prostate biopsy in clinical practice: sampling, labeling and specimen processing. J Urol 2013;189:2039-46. [CrossRef]

19. Schoots IG, Roobol MJ, Niebboer D, Bangma CH, Steyerberg EW, Hunink MG. Magnetic resonance imaging-targeted biopsy may enhance the diagnostic accuracy of significant prostate cancer detection compared to standard transrectal ultrasoundguided biopsy: a systematic review and meta-analysis. Eur Urol 2015;68:438-50. [CrossRef]

20. De Nunzio C, Lombardo R, Presicce F, Bellangino M, Finazzi Agro $\mathrm{E}$, Gambrosier MB, et al. Transrectal-ultrasound prostatic biopsy preparation: rectal enema vs. mechanical bowel preparation. Cent European J Urol 2015;68:223-8. [CrossRef] 